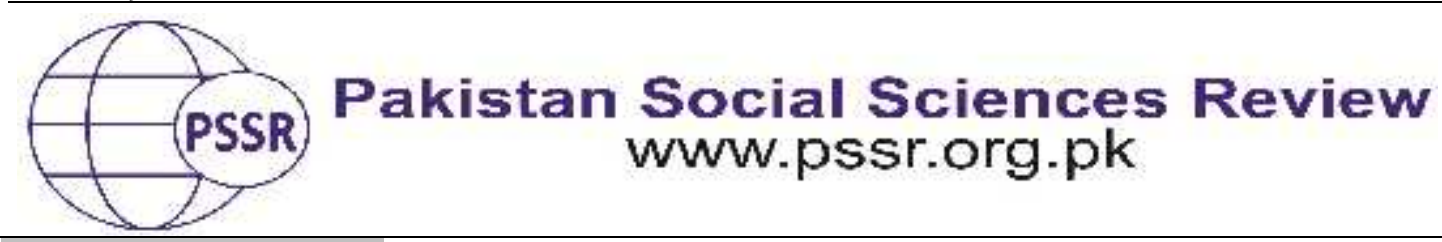

RESEARCH PAPER

\title{
Predictive role of Personality Traits and Self Control in Mental Health and Academic Achievement among Adolescents Playing Online Games
}

\author{
Ryesa Qaisar ${ }^{1}$ Dr. Khalid Mahmood ${ }^{2^{\star}}$ Syed Muhammad Imran Haider Zaidi ${ }^{3}$
}

1. MS Clinical Psychology, Department of Applied Psychology, Govt. College University Faisalabad, Punjab, Pakistan

2. Assistant Professor, Department of Applied Psychology, Govt. College University Faisalabad, Punjab, Pakistan

3. Assistant Professor, Department of Applied Psychology, Govt. College University Faisalabad, Punjab, Pakistan

\begin{tabular}{|c|c|}
\hline PAPER INFO & ABSTRACT \\
\hline $\begin{array}{l}\text { Received: } \\
\text { March 18, } 2021 \\
\text { Accepted: } \\
\text { June } 05,2021 \\
\text { Online: } \\
\text { June } 10,2021\end{array}$ & $\begin{array}{l}\text { The present research explores the effect of online gaming on } \\
\text { personality traits, self-control, mental health and academic } \\
\text { achievement. The population of the study consisted of the } \\
\text { adolescents who play online games. A sample of } 308(N=308) \\
\text { adolescents were selected by using purposive sampling }\end{array}$ \\
\hline $\begin{array}{l}\text { Keywords: } \\
\text { Academic } \\
\text { Achievement, } \\
\text { Mental Health, } \\
\text { Online Games, } \\
\text { Personality Traits, } \\
\text { Self-Control }\end{array}$ & $\begin{array}{l}\text { Inventory (John \& Srivastava, 1999). Self-control scale(Tangney } \\
\text { et al. 2004), and Mental Health Questionnaire (Dubey \& Singh, } \\
\text { 2016) were used to collect the data in current research. The } \\
\text { results of correlation showed that personality traits } \\
\text { extraversion, agreeableness conscientiousness, and openness } \\
\text { were significantly positively correlated with self-control, mental }\end{array}$ \\
\hline $\begin{array}{l}\text { *Corresponding } \\
\text { Author }\end{array}$ & $\begin{array}{l}\text { health, and academic achievement and neuroticism was } \\
\text { negatively but significantly related to self-control, mental } \\
\text { health, and academic achievement. The results of multiple } \\
\text { regression analysis exhibited that personality traits } \\
\text { (extraversion, agreeableness, conscientiousness, and openness) } \\
\text { and self-control were confirmed to be significant predictors of } \\
\text { mental health and Personality traits (extraversion, neuroticism, } \\
\text { openness) and self-control were shown to be significant } \\
\text { predictors of academic achievement. }\end{array}$ \\
\hline
\end{tabular}

\section{Introduction}

An online game is a game played either partly or mostly over the internet or some other available computer network. These games feature PCs, consoles and handheld devices in a wide variety of different formats, from shooters tactics and huge multiplayer online role-playing games. These mobile games effects the 
individual both psychological and physically. Adolescents are most effective age group of online games. Playing online games increase the aggression and frustration level with low self-control lead to poor mental health. Adolescents spend most of their time on playing online games and this boost the level of procrastination and cause low academic achievement. Playing online games increase the exposure of the screen with this reliance on video games disrupts normal sleep habits and leads to less overall sleep, longer sleep periods and more sleep interruptions (Hale \& Guan, 2015; Higuchi et al. 2005; Hysing et al. 2015).

Excessive playing video games can be short-term or long-term in adolescents with emotional and neurological consequences (Higuchi et al. 2005; Meng et al. 2015; Spada\&Caselli 2017). Positive relationships between Online Gaming and mental health issues have also been identified in previous studies (Liu et al. 2018; Wu et al. 2018). The essential video game behavior predictors of individual biological and psychological variables highlighted by Wood (2008).

The personality consists of integrated psychological features and structures that have an effect on one person's relationship with the intra-psychic, physical and social conditions, and on adaptations (Larsen\&Buss, 2005).Every single person has a unique personality shaped by the interaction of different traits. The basic principle of traits is to consider and evaluate these individual characteristics of personality (Feldman, 2005).

An overall conceptual structure for these five traits in personality psychology should incorporate all the research results and theory. The Big Five traits are also called the "Five Factor Model" or FFM. McCrae also concluded that the five main characteristics are also global. Resources from over 50 different cultures have shown that personalities can be represented beautifully through the broad five features suggest that neuroticism is connected to the management of disagreeable events such as concern and dejection. It is the propensity for negative emotions, such as anger and depression (Fiske, 1949; Smith, 1967; Goldberg, 1981;McCrae\& Costa, 1987).

Self-control can be viewed both as an individual trait factor and as a contextual factor which may vary through different tasks, as the level of difficulty of tasks changes as a result of resisting one's impulses and as the temporal sequence of tasks require sequential use of self-control. In addition to anger management and binge eating, self-control has been associated with moral standards and integrity. Recent self-control studies focused on the impact of self-control on fraud and lying actions of both middle and high school students and found that both low self-control and short-term self-control are linked to fraud and lying (Mead et. al. 2009).

Consistent with other theories, self-control refers to the human capacity to suppress immediate thoughts, attempts and desires in pursuit of more or less global or long term targets. Self-control, therefore, is a kind of auto regulation (Fujita, 2011).In 2011, Gatab et al. conducted research and explained mental health as a 
situation where psychological maturity simply is identified as the definition and situation for the perception and acquirement of knowledge and maturity that is simply contrary to full efficacy, personal productivity and satisfaction of social interaction. In all statistics including psychological, physical and social experiences, it also includes constructive thoughts about the health behavior (Gatab, 2011).

Academic achievement is generally expressed in tertiary or undergraduate universities as the grade-point average (GPA) mean marks applied to weighted courses that lead to final degree evaluation. The GPA is the primary selection criterion and predictive criterion for postgraduate work and employment (Strenze, 2007).

Personality is believed to have a significant effect on your mental health. Second, by indirectly influencing people's objective wellbeing, for example by influencing personality's physiological reactions to stress. Second, personality characteristics determine the psychoactive offenders' objective health status and are risk factors (Felitti et al. 1998 \& Kodl et al. 2004).

A large number of studies show that academic achievement and conscientiousness are related in a positive way (Komarraju et. al. 2009). This attribute is higher than intelligence factors in (Duckworth \& Seligman, 2005). Extroversion is one of the most important variables of personality with academic success. Studies also show that openness is related to academic achievement (Paunonen\& Ashton, 2001).

Multiply academic success is established: research competencies and learning policies that are separate from self-control predict school performance (Crede \& Kuncel, 2008, Hattie et al. 1996). Emotional factors as mathematical anxiety are also important (Foley et al. 2017) and particularly demanding objectives need to be accomplished over months and years (Eskreis-Winkler et. al. 2016b).

\section{Hypotheses}

1. There would be a significant relationship between personality traits, selfcontrol, mental health and academic achievement among adolescents playing online games.

2. Mental health and academic achievement would be significant predicted by personality traits and self-control of adolescents playing online games.

\section{Material and Methods}

\section{Participant}

Adolescents playing video games were the population of the sample. By use of purposive sampling methods from various areas of Punjab, a sample of 308 
$(\mathrm{N}=308)$ adolescentswere selected. The sample was further divided into two parts: 174 men and 134were women.In the present research, the design of co relational research was used.

\section{Instruments}

\section{Demographic Data Sheet}

Demographic data sheet was to be established, social economic status, family life and climate.

\section{Big Five Personality Inventory}

44-item inventory that measures an individual in terms of personality's Big Five Factors (dimensions). Aspect is divided into the facets of personality. Big Five Dimensions (Factors) are Extraversion, Agreeableness, Conscientiousness, Neuroticism and openness (John \&Srivastava, 1999). The good range of reliabilities analysis indicate that Cronbach's a =Neuroticism,.90; Extraversion, .89; Agreeableness, .86; Conscientiousness, .90 and openness, .90 .

\section{Self-Control Scale}

The self-control scale in this study was reorganized from the scale that Gottfredson and Hirschi originally developed (Cronbach's a, 0.74). There were a total of 20 questions, ten reflecting the degree of long-term satisfaction and the other 10 reflecting the degree of immediate satisfaction. A five point Likert scale listed all 20 objects by respondents. In determining the total score, the last 10 items (point number 11-20) were reversed. A higher overall score indicates a higher self-control level (Tangney et. al. 2004).

\section{Mental Health Questionnaire}

Mental health questionnaire is developed by Dubey and Singh (2016) containing 19 items. This scale is develop to measure the mantel health of the individuals in which responded have to rate their feeling regarding give questions on a 5 point likert form strongly disagree as 0 and strongly agree as 4 . The results of reliability analysis indicate that Cronbach's $\alpha=.826$

\section{Academic Achievement}

Academic achievement here is calculated as percentage of last class result of respondents. Same idea was endorsed by khan et al. (2012) in their research and Ali and colleagues (2016). Both of these studies considered percentage of last class result as an academic achievement. Therefore, in this research academic achievement was measured through percentage/GPA of last class result. 


\section{Procedure}

First of all permission for the scale was taken from the original authors. Individual consent was obtained prior to data collection from the participants. This was accompanied by ethical and legal consideration. Due to pandemic situation of Corona virus, the data were collected online through Google form. All study questionnaire with informed consent and demographic sheet were added to Google form and instructions were also given to respondents both verbally and written form.First instructions were given to respondent about the purpose of research and then questionnaires were deceived to respondents. Enough time was given to respondent to response on questionnaires. They offered withdraw opportunity at any time during data collection. After the desire level of sample, the data collection process was stopped and file of data sheet in MS Excel was downloaded from Google form after that the file was converted in two SPSS and necessary codes were added according to demographic sheet such as in gender 1 was labeled for male and 2 was added for female to convert the data into numeric values, same this activity was performed in questionnaires to convert the response from strongly agree to assigned digit values according the scoring criteria of each questionnaire. After that data were analyzed through SPSS.

\section{Results and Discussion}

Table 1

Frequency of Demographic Variables $(\mathrm{N}=308)$

\begin{tabular}{cccc}
\hline \multicolumn{2}{c}{ Respondent's Characteristics } & $f(\%)$ & $\boldsymbol{M}(\mathrm{SD})$ \\
\hline Age & & & $17.26(1.75)$ \\
\hline \multirow{2}{*}{ Gender } & Male & $174(56.5)$ \\
& Female & $134(43.5)$ \\
\hline \multirow{2}{*}{ Family System } & Nuclear System & $140(45.5)$ \\
& Joint System & $168(54.5)$ \\
\hline \multirow{4}{*}{ Which type of online game you are playing } & 8 Ball Pool & $34(11.0)$ \\
& Candy Crash & $74(24.0)$ \\
& Fortnite & $20(6.5)$ \\
& Ludu Star & $92(29.9)$ \\
& PUBG & $88(28.6)$ \\
\hline
\end{tabular}

The results of table (1) indicated that the average age of respondents was $($ Mean $=17.26$ with SD = 1.75). Whereas in gender, $174(56.5 \%)$ were male participated in this research and $134(43.5 \%)$ were female participated in this research. Meanwhile in family system, $140(45.5 \%)$ were participated from nuclear family and 168 (54.5\%) were participated from joint family in this research. However, on the question of "Which type of online game you are playing", respondents respond; $34(11.0 \%)$ respondents were played 8 Ball Pool online game, $74(24.0 \%)$ respondents were played Candy Crash online game, 20 (6.5\%) 
respondents were played Fortine online game, 92 (29.9\%) respondents were played Ludu Star online game and 88 (28.6\%) respondents were played PUBG online game.

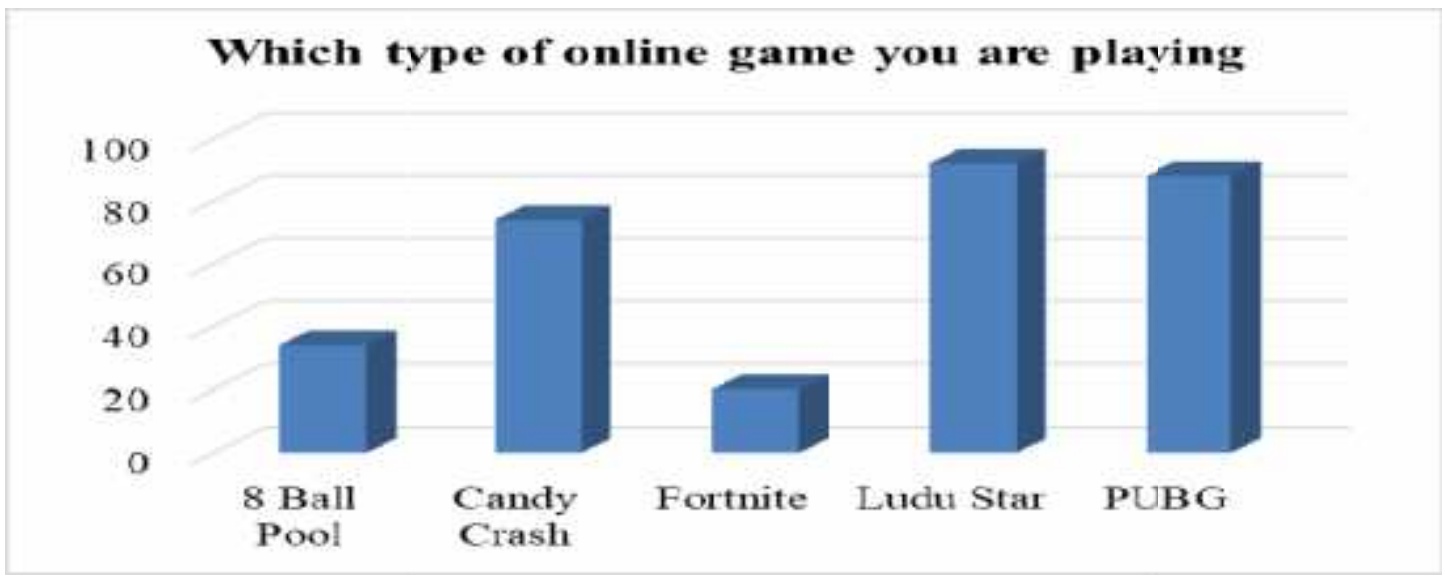

Figure 1

Frequency Distribution of Which type of online game you are playing $(N=308)$

On the question of "Which type of online game you are playing", respondents respond; $34(11.0 \%)$ respondents were played 8 Ball Pool online game, $74(24.0 \%)$ respondents were played Candy Crash online game, 20 (6.5\%) respondents were played Fortine online game, 92 (29.9\%) respondents were played Ludu Star online game and $88(28.6 \%)$ respondents were played PUBG online game.

Table 2

Psychometric Statistics and Descriptive Statistics $(\mathrm{N}=308)$

\begin{tabular}{cccccccc}
\hline \multirow{2}{*}{ Variables } & \multirow{2}{*}{$\boldsymbol{M}$} & \multirow{2}{*}{ SD } & \multicolumn{7}{c}{ Range } \\
\cline { 5 - 9 } & & & $\boldsymbol{a}$ & Minimum & Maximum & Skew & Kurt \\
\hline Extraversion & 25.90 & 7.20 & .72 & 8 & 40 & -.76 & .34 \\
\hline Agreeableness & 29.61 & 6.73 & .71 & 10 & 45 & -.47 & -.39 \\
\hline Conscientiousness & 29.51 & 5.20 & .76 & 14 & 45 & .03 & .04 \\
\hline Neuroticism & 25.63 & 6.81 & .70 & 8 & 40 & -.33 & -.19 \\
\hline Openness & 36.71 & 7.89 & .75 & 10 & 50 & -.58 & -.16 \\
\hline Self-Control & 32.69 & 8.18 & .80 & 10 & 50 & -1.09 & .91 \\
\hline Mental Health & 63.95 & 10.25 & .74 & 19 & 95 & .22 & .96 \\
\hline $\begin{array}{c}\text { Academic } \\
\text { Achievement }\end{array}$ & 77.52 & 10.66 & - & 50 & 99 & -.25 & -.36 \\
\hline
\end{tabular}

Skew $=$ Skewness; Kurt $=$ Kurtosis

The result in table (2) confirmed that the overall respondents showed that they have high level of openness personality trait with high level of self-control and good mental health. While in the internal consistency (reliability analysis) of all questionnaires from this research showed in adequate range of Cronbach's alpha (.70 to .80 ). Whereas, the values and skewness and kurtosis were also revealed acceptable range for the normality of data. 
Table 3

Inter-Correlation in Personality Traits, Self-Control, Mental Health and Academic Achievement $(\mathrm{N}=308)$

\begin{tabular}{lcccccccc}
\hline & $\mathbf{1}$ & $\mathbf{2}$ & $\mathbf{3}$ & $\mathbf{4}$ & $\mathbf{5}$ & $\mathbf{6}$ & $\mathbf{7}$ & $\mathbf{8}$ \\
\hline 1.Extraversion & - & $.73^{* *}$ & $.54^{* *}$ & $-.33^{* *}$ & $.39^{* *}$ & $.41^{* *}$ & $.52^{* *}$ & $.34^{* *}$ \\
\hline 2.Agreeableness & & - & $.66^{* *}$ & $-.22^{* *}$ & $.44^{* *}$ & $.36^{* *}$ & $.55^{* *}$ & $.29^{* *}$ \\
\hline 3.Conscientiousness & & & - & $-.15^{* *}$ & $.44^{* *}$ & $.29^{* *}$ & $.52^{* *}$ & $.26^{* *}$ \\
\hline 4.Neuroticism & & & & - & $-.24^{* *}$ & $-.45^{* *}$ & $-.21^{* *}$ & $-.20^{* *}$ \\
\hline 5.Openness & & & & & - & $.32^{* *}$ & $.43^{* *}$ & $.29^{* *}$ \\
\hline 6.Self-Control & & & & & - & $.32^{* *}$ & $.14^{*}$ \\
\hline 7.Mental Health & & & & & - & $.21^{* *}$ \\
\hline 8.Academic Achievement & & & & & & & - \\
${ }^{* *} \mathrm{p}<.01 ;{ }^{*} \mathrm{p}<.05$ & & & & & & &
\end{tabular}

The results in table 3 showed that extraversion (personality trait) was positively as well significantly correlated with agreeableness $(\mathrm{r}=.73)$, conscientiousness $(r=.54)$, openness $(r=.39)$, self-control $(r=.41)$, mental health $(r=$ .52) and academic achievement $(r=.34)$. While, extraversion was negatively but significantly correlated with neuroticism $(\mathrm{r}=-.33)$. Whereas, agreeableness (personality trait) was positively as well significantly correlated with conscientiousness $(\mathrm{r}=.66)$, openness $(\mathrm{r}=.44)$, self-control $(\mathrm{r}=.36)$, mental health $(\mathrm{r}=$ $.55)$ and academic achievement $(r=.29)$. Meanwhile, agreeableness was negatively but significantly correlated with neuroticism $(\mathrm{r}=-.22)$. However, conscientiousness (personality trait) was positively as well significantly correlated with openness $(\mathrm{r}=$ $.44)$, self-control $(r=.29)$, mental health $(r=.52)$ and academic achievement $(r=.26)$. Meanwhile, conscientiousness was negatively but significantly correlated with neuroticism $(\mathrm{r}=-.15)$. Though, neuroticism (personality trait) was negatively but significantly correlated with openness $(r=-.24)$, self-control $(r=-.45)$, mental health $(\mathrm{r}=-.21)$ and academic achievement $(\mathrm{r}=-.20)$. Although, openness (personality trait) was positively as well significantly correlated with self-control $(r=.32)$, mental health $(r=.43)$ and academic achievement $(r=.29)$. While, self-control was positively as well significantly correlated with mental health $(r=.32)$ and academic achievement $(r=.14)$. Finally, mental health was positively as well significantly correlated with and academic achievement $(\mathrm{r}=.21)$.

Table 4

For the Predict of Personality Traits and Self-control in Mental Health (N=308)

\begin{tabular}{cccc}
\hline & \multicolumn{3}{c}{ Mental Health } \\
\hline Predictors & $\boldsymbol{B}$ & $\boldsymbol{\beta}$ & $\mathbf{9 5 \%} \boldsymbol{C I}$ \\
\hline Constant & $26.54^{* *}$ & & {$[18.10,34.98]$} \\
\hline Extraversion & $.27^{* *}$ & .19 & {$[.07, .46]$} \\
\hline Agreeableness & $.26^{* *}$ & .17 & {$[.04, .49]$} \\
\hline Conscientiousness & $.43^{* *}$ & .22 & {$[.19,66]$} \\
\hline Neuroticism & -.01 & -.01 & {$[-.16 . .14]$} \\
\hline Openness & $.21^{* *}$ & .16 & {$[.08, .35]$} \\
\hline
\end{tabular}




\begin{tabular}{cccc}
\hline Self-Control & $.08^{*}$ & .07 & {$[.05, .22]$} \\
\hline $\mathrm{R}^{2}$ & .40 & & \\
\hline $\mathrm{F}$ & $33.07^{* *}$ & \\
\hline
\end{tabular}

${ }^{*} \mathrm{p}<.05 ;{ }^{* *} \mathrm{p}<.01 ; \mathrm{B}=$ Unstandardized Coefficients; $\beta$ =Standardized Coefficients; $\mathrm{CI}=$ Confidence Interval

The results of table (4) exhibited that personality traits (big five) and selfcontrol were confirmed to be significant predictors of mental health and contribute overall $40 \%$ of variance $\left(\mathrm{R}^{2}=.40\right)$. Meanwhile, extraversion $(\beta=.19)$, agreeableness $(\beta=.17)$, conscientiousness $(\beta=.22)$, openness $(\beta=.16)$ and self-control $(\beta=.07)$ revealed significant predictors in mental health of respondents.

Table 5

For the Predict of Personality Traits and Self-control in Academic Achievement $(\mathrm{N}=308)$

\begin{tabular}{cccc}
\hline & \multicolumn{3}{c}{ Academic Achievement } \\
\cline { 4 - 4 } Predictors & $\boldsymbol{B}$ & $\boldsymbol{\beta}$ & $\mathbf{9 5 \%}$ CI \\
\hline Constant & 64.05 & & {$[53.66,74.45]$} \\
Extraversion & $.33^{* *}$ & .23 & {$[.09, .57]$} \\
Agreeableness & .03 & .02 & {$[-.25, .30]$} \\
Conscientiousness & .12 & .06 & {$[-.17, .41]$} \\
Neuroticism & $-.17^{*}$ & -.11 & {$[-.36,-.02]$} \\
Openness & $.22^{* *}$ & .17 & {$[.06, .39]$} \\
Self-Control & $.10^{*}$ & .08 & {$[.06, .26]$} \\
$\mathrm{R}^{2}$ & .16 & & \\
$\mathrm{~F}$ & $9.24^{* *}$ & & \\
\hline
\end{tabular}

${ }^{*} p<.05 ;{ }^{* *} p<.01 ; \mathrm{B}=$ Unstandardized Coefficients; $\beta=$ Standardized Coefficients; $C I=$ Confidence Interval

The results of table (5) exhibited that personality traits (big five) and selfcontrol were confirmed to be significant predictors of academic achievement and contribute overall $16 \%$ of variance $\left(\mathrm{R}^{2}=.16\right)$ in academic achievement. Meanwhile, extraversion $(\beta=.23)$, neuroticism $(\beta=-.11)$, openness $(\beta=.17)$ and self-control $(\beta=.08)$ revealed significant predictors in academic achievement of respondents.

\section{Discussion}

The aim of this research is to measure the personality traits, self-control, mental health and academic achievement among adolescents playing online games.Teenagers playing video games will be the population of the sample. By use of purposive sampling methods from various areas of Punjab, a sample of 308 $(\mathrm{N}=308)$ adolescents could be selected. The sample is divided into two parts: 174 are men and 134 are women.Thisstudy involved teenage people from various areas who play video games online. In the current study, both men and women were included. The present research involved all adolescents (nuclear and shared family structures). 
In the research, adults are excluded. Adolescents from various areas not playing video games have also not been included in the sample. The present research has omitted adolescents with any medical or psychological condition.

Three questionnaires were used in this research; Big five Personality Inventory,TheSelf-Control Scale, TheMental Health Questionnaire. While academic achievement calculated as percentage of last class result of respondents.

The results of table (4.1) indicated that the average age of respondents was $($ Mean $=17.26$ with $\mathrm{SD}=1.75)$. Whereas in gender, $174(56.5 \%)$ were male participated in this research and $134(43.5 \%)$ were female participated in this research. Meanwhile in family system, 140 (45.5\%) were participated from nuclear family and 168 (54.5\%) were participated from joint family in this research. However, on the question of "Which type of online game you are playing", respondents respond; $37(11.0 \%)$ respondents were played 8 Ball Pool online game, $74(24.0 \%)$ respondents were played Candy Crash online game, 20 (6.5\%) respondents were played Fortine online game, 92 (29.9\%) respondents were played Ludu Star online game and 88 (28.6\%) respondents were played PUBG online game.

It was confirmed that the overall respondents showed that they have high level of openness personality trait with high level of self-control and good mental health. While in the internal consistency (reliability analysis) of all questionnaires from this research showed in adequate range of Cronbach's alpha (.70 to .80). Whereas, the values, skewness and kurtosis were also revealed acceptable range for the normality of data.

The results of correlation indicated for Hypothesis 1 that extraversion (personality trait) was positively as well significantly correlated with agreeableness, conscientiousness, openness, self-control, mental health and academic achievement. While, extraversion was negatively but significantly correlated with neuroticism. Whereas, agreeableness (personality trait) was positively as well significantly correlated with conscientiousness, openness, self-control, mental health and academic achievement. Meanwhile, agreeableness was negatively but significantly correlated with neuroticism. However, conscientiousness (personality trait) was positively as well significantly correlated with openness, self-control, mental health and academic achievement. Meanwhile, conscientiousness was negatively but significantly correlated with neuroticism. Though, neuroticism (personality trait) was negatively but significantly correlated with openness, self-control, mental health and academic achievement. Although, openness (personality trait) was positively as well as significantly correlated with self-control, mental health and academic achievement. While, self-control was positively as well significantly correlated with mental health and academic achievement. Finally, mental health was positively as well significantly correlated with and academic achievement. Past studies have shown that these various personality traits are closely linked to aspects of mental health. 
Whereas, previous studies have shown that characteristics contribute to academic performance. Bakar and Herng (2018) have shown that the academic success of students is related to their attractiveness, sensitivity, extraversion, and neuroticism. Further research has shown that students are more able to attain academic results with the character of chance, extraversion and conscience and without persistent emotional problems. In other words, unique characteristics such as extraversion, conscientiousness and the mental wellbeing of students must be addressed in order to enhance the student's achievement.

Caspi et al. (2005) sheds light on the mechanisms that may explain the relationship between personality and academic achievement; they suggest the relationship between personality and academic achievement can be charming; i.e. people prefer environments compatible with their personality; Some studies have shown that academic performance has been good in terms of openness to learning, quality and extroversion and negative neuroticism (Laidra et. al . 2007; Lounsbury et al. 2003a). The results of the present study are in line with above reposted past researches, so this hypothesis is accepted.

The results of multiple regression analysis revealed for Hypothesis 2 that found personality traits (big five) and self-control were confirmed to be significant predictors of mental health. Meanwhile, extraversion $(\beta=.19)$, agreeableness $(\beta=.17)$, conscientiousness $(\beta=.22)$, openness $(\beta=.16)$ and self-control $(\beta=.07)$ revealed significant predictors in mental health of respondents. In 2013, Haghrangbar et. al. reported that people with high levels of conscientiousness and agreeableness have better mental health. The relationship between the markers of mental health and personality, based on Big Five, was different. In neurotics, for example, concepts like pessimism and negative emotion have been closely linked to this cause, leading to negative perceptions of the health situation in individuals. Higher extraversion levels have, however, linked positive emotional experiences: better public health assessment, increased physical fitness and greater satisfaction with life. There were also high levels of understanding with a higher degree of public health and mental wellbeing. The versatility and alignment of public health measures received less consideration compared to the above three factors. The results of the present study are same as above reposted past researches, so this hypothesis is accepted.

Additionally, the results of multiple regression showed the results of Hypothesis 2 that confirmed personality traits (big five) and self-control were confirmed to be significant predictors of academic achievement. Meanwhile, extraversion $(\beta=.23)$, neuroticism $(\beta=-.11)$, openness $(\beta=.17)$ and self-control $(\beta=.08)$ revealed significant predictors in academic achievement of respondents.Some studies have shown that openness is related to academic achievement (Paunonen \& Ashton, 2001). The strong, weak association of those variables was stated by Duff et al. (2004). As friendly people are extremely cooperative, helpful and able to cooperate efficiently with others, there are no far-reaching positive connections between compassion and academic achievement. The more gratifying students seem to have higher graduates' and therefore higher academic achievements (Furnham, et 
al. 2006). The results of this study are partially significant, so this hypothesis is partially accepted.

\section{Conclusion}

The current study was planned to investigate of the prediction of personality traits and self-control of young people who play online games on mental health and academic achievement. In total $308(N=308)$ adolescents could be selected with range of 174 are male and 134 are female. The results of reliability analysis reported all the scale were reliable and were suitable for this research. Relationship found that personality traits such as that extraversion, agreeableness, conscientiousness, openness were significantly positively correlated with self-control, mental health, and academic achievement. Whereas, neuroticism as personality traits revealed negative but significant correlated with extraversion, agreeableness, conscientiousness, openness, self-control, mental health, and academic achievement. Self-control also stand positive significant linked with mental health and academic achievement.In multiple regression analysis, extraversion, agreeableness, conscientiousness, openness and self-control found significant predictor of mental health and academic achievement. 


\section{Reference}

Ali, M. A. Mahsud, N. K. Khan, W.\&Naz, A. (2016).War against Terrorism and its Impact on Children's Academic Performance in District Swat Khyber Pakhtunkhwa Pakistan. Journal of Management Info, 9(1), 12-20

Bakar, Z. A.\&Herng, T. C. (2018). Relationships Between Personality Traits and Academic Achievement Among Primary School Students in Johor, Malaysia. Advanced Science Letters, 24(5), 3512-3515.

Caspi, A. Roberts, B. W.\& Shiner, R. L. (2005). Personality development: Stability and change. Annu. Rev. Psychol. 56, 453-484.

Credé, M. \& Kuncel, N. R. (2008). Study habits, skills, and attitudes: The third pillar supporting collegiate academic performance. Perspectives on psychological science, 3(6), 425-453.

Duckworth, A. L.\& Seligman, M. E. (2005). Self-discipline outdoes IQ in predicting academic performance of adolescents. Psychological science, 16(12), 939-944.

Duff, A. Boyle, E. Dunleavy, K.\& Ferguson, J. (2004). The relationship between personality, approach to learning and academic performance. Personality and individual differences, 36(8), 1907-1920.

Dunsmore, J. A. (2005). An investigation of the predictive validity of broad and narrow personality traits in relation to academic achievement, University of Tennessee, Knoxville

Eskreis-Winkler, L. Gross, J. J.\& Duckworth, A. L. (2016). Grit: Sustained selfregulation in the service of superordinate goals. Handbook of self-regulation: Research, theory and applications. New York, NY: Guilford.

Felitti, V. J. Anda, R. F. Nordenberg, D. Williamson, D. F. Spitz, A. M. Edwards, V.\& Marks, J. S. (1998). Relationship of childhood abuse and household dysfunction to many of the leading causes of death in adults: The Adverse Childhood Experiences (ACE) Study. American journal of preventive medicine, 14(4), 245-258.

Fiske, D. W. (1949). Consistency of the factorial structures of personality ratings from different sources. The Journal of Abnormal and Social Psychology, 44(3), 329-344

Fujita, K. (2011). On conceptualizing self-control as more than the effortful inhibition of impulses. Personality and social psychology review, 15(4), 352-366.

Furnham, A. Chamorro-Premuzic, T.\& McDougall, F. (2003).Personality, cognitive ability, and beliefs about intelligence as predictors of academic performance. Learning and individual Differences, 14(1), 47-64. 
Gottfredson, M. R.\&Hirschi, T. (2003). Self-control and opportunity: Control theories of crime and delinquency.Advances in criminological theory 12. New Brunswick. Transaction Publishers.

Hale, L.\& Guan, S. (2015). Screen time and sleep among school-aged children and adolescents: a systematic literature review. Sleep medicine reviews, 21, 50-58.

Hattie, J. Biggs, J.\&Purdie, N. (1996). Effects of learning skills interventions on student learning: A meta-analysis. Review of educational research, 66(2), 99-136.

Higuchi, S. Motohashi, Y. Liu, Y.\& Maeda, A. (2005). Effects of playing a computer game using a bright display on presleep physiological variables, sleep latency, slow wave sleep and REM sleep. Journal of sleep research, 14(3), 267-273.

Hysing, M. Pallesen, S. Stormark, K. M. Jakobsen, R. Lundervold, A. J.\&Sivertsen, B. (2015). Sleep and use of electronic devices in adolescence: results from a large population-based study. BMJ open, 5(1), e006748.

John, O. P.\&Srivastava, S. (1999). The Big-Five trait taxonomy: History, measurement, and theoretical perspectives (Vol. 2, 102-138). Berkeley: University of California.

Khan, A. A. Saleem, M. Tahir, M. A.\&Nadeem, M. (2012). Emotional Intelligence and Self-Esteem as Predictors of Academic Success among Higher Education Students: A Survey Conducted at the Islamia University of Bahawalpur, Pakistan. Journal of Educational Research, 15(1), 56.

Kodl, M. M.\&Mermelstein, R. (2004). Beyond modeling: Parenting practices, parental smoking history, and adolescent cigarette smoking. Addictive behaviors, 29(1), 1732.

Komarraju, M. Karau, S. J.\&Schmeck, R. R. (2009).Role of the Big Five personality traits in predicting college students' academic motivation and achievement. Learning and individual differences, 19(1), 47-52.

Laidra, K.Pullmann, H.\&Allik, J. (2007). Personality and intelligence as predictors of academic achievement: A cross-sectional study from elementary to secondary school. Personality and individual differences, 42(3), 441-451.

Larsen, R. J.\& Buss, D. M. (2005).Personality psychology: Domains of knowledge about human nature (2nd Ed.). New York: McGraw Hill.

Liu, L. Yao, Y. W. Li, C. S. R. Zhang, J. T. Xia, C. C. Lan, J. ... \& Fang, X. Y. (2018). The comorbidity between internet gaming disorder and depression: Interrelationship and neural mechanisms. Frontiers in psychiatry, 9(1), 154-164. 
Lounsbury, M. Ventresca, M.\& Hirsch, P. M. (2003). Social movements, field frames and industry emergence: a cultural-political perspective on US recycling. Socioeconomic review, 1(1), 71-104.

McCrae, R. R.\& Costa, P. T. (1987).Validation of the five-factor model of personality across instruments and observers. Journal of Personality and Social Psychology, 52(1), 81-90

Mead, N. L. Baumeister, R. F. Gino, F. Schweitzer, M. E.\&Ariely, D. (2009).Too tired to tell the truth: Self-control resource depletion and dishonesty. Journal of experimental social psychology, 45(3), 594-597.

Meng, Y. Deng, W. Wang, H. Guo, W.\& Li, T. (2015). The prefrontal dysfunction in individuals with Internet gaming disorder: a meta-analysis of functional magnetic resonance imaging studies. Addiction biology, 20(4), 799-808.

Mischel, W. Shoda, Y.\&Peake, P. K. (1988).The nature of adolescent competencies predicted by preschool delay of gratification. Journal of Personality and Social Psychology, 54(4), 687-696

Ng, T. W. Eby, L. T. Sorensen, K. L.\& Feldman, D. C. (2005). Predictors of objective and subjective career success: A meta-analysis. Personnel psychology, 58(2), 367408.

Paunonen, S. V.\& Ashton, M. C. (2001).Big Five predictors of academic achievement. Journal of Research in Personality, 35(1), 78-90.

Rezaei, A.\&Gatab, T. A. (2011). Relationship between mental health and its impact on family's aggressive students boys and girls. European Psychiatry, 26(S2), 882882.

Singh, G.\&Dubey, A. (2016). Mental health and well-being of caregivers: A review of the literature. The International Journal of Indian Psychology, 3(57), 98-105.

Smith, G. M. (1967). Usefulness of peer ratings of personality in educational research. Educational and Psychological measurement, 27(4), 967-984.

Strenze, T. (2007). Intelligence and socioeconomic success: A meta-analytic review of longitudinal research. Intelligence, 35(5), 401-426.

Tangney, J. P. Baumeister, R. F.\& Boone, A. L. (2004). High self-control predicts good adjustment, less pathology, better grades, and interpersonal success. Journal of personality, 72(2), 271-324.

Wu, A. M. Chen, J. H. Tong, K. K. Yu, S.\& Lau, J. T. (2018).Prevalence and associated factors of Internet gaming disorder among community dwelling adults in Macao, China. Journal of behavioral addictions, 7(1), 62-69. 
Spada, M. M.\&Caselli, G. (2017). The metacognitions about online gaming scale: Development and psychometric properties. Addictive behaviors, 64, 281-286.

Goldberg, L. R. (1981). Language and individual differences: The search for universals in personality lexicons. Review of personality and social psychology, 2(1), 141-165. 